\title{
Memória Institucional e Arquivologia: uma discussão teórico-metodológica
}

\author{
Ivana Parrela ${ }^{I}$
}

Adalson Nascimento ${ }^{\text {II }}$

https://orcid.org/0000-0002-4859-4544

\begin{abstract}
IUniversidade Federal de Minas Gerais, Belo Horizonte, MG, Brasil. Professora Associada do Departamento de Teoria e Gestão da Informação, da Escola de Ciência da Informação da UFMG.

${ }^{I I}$ Universidade Federal de Minas Gerais, Belo Horizonte, MG, Brasil. Professor Adjunto do Departamento de Organização e Tratamento da Informação, da Escola de Ciência da Informação da UFMG.
\end{abstract}

http://dx.doi.org/10.1590/1981-5344/3901

Este artigo analisa a construção do conceito de memória institucional na Ciência da Informação e, em especial, discute a memória na Arquivologia e nas instituições arquivísticas públicas e privadas. Demonstra-se que o surgimento de Centros de Memória no Brasil, na década de 1970, está associado à valorização da memória institucional, que se tornou, então, vital para as organizações. Diferente da memória organizacional, mais mutável e identificada com a eficácia, está ligada à legitimidade, à identidade e à responsabilidade histórica dos produtores nas instituições. Ela pode ser (re)construída por meio dos arquivos, ainda que não se confunda com eles.

Palavras-chave: Arquivologia. Memória. Memória institucional.

\section{Institutional Memory and Archival Science: a theoretical-methodological debate}


The present paper analyzes the development of the concept of institutional memory in Information Science and discusses the issue of memory in Archival Science as well as public and private archival institutions. This study aimed to demonstrate that the emergence of Memory Centers in Brazil over the 1970s is associated to the importance given to institutional memory which, in turn, became vital to organizations. Unlike constantly changing and efficacy-related organizational memory, institutional memory has to do with the historical responsibility of intitutional producers. It might be (re)constructed by means of archives.

Keywords: Archival Science. Memory. Institutional memory.

\section{A construção do objeto na Ciência da Informação: Icléia Thisen}

Nas pesquisas realizadas para a elaboração deste trabalho, encontraram-se poucas definições específicas sobre memória institucional. Invariavelmente, seu significado aparece associado aos termos memória organizacional e memória empresarial. O Dicionário de Administração, de Lacombe (2004) utiliza-se de remissiva que encaminha o leitor para os termos instituição e organização.

O trabalho mais abrangente sobre o tema em português é a tese de Icléia Thisen, dos anos de 1990, hoje publicada em livro com o título Memória institucional. Para a autora, "se a instituição existe, a memória se plasma" (THIESEN, 2013, p. 26). Para pensar como se dá o fenômeno da memória no contexto institucional, Thiesen sustenta que é necessário entender o que vem a ser uma instituição. Nesse percurso, lança mão de conceitos focaultianos. Para a autora, as instituições são encaradas como formas fundamentais de saber-poder. Com citações de várias obras do Foucault ao longo do trabalho, define a relação de poder e saber como não necessariamente vinculada a esta ou àquela forma de saber, mas destaca que exercer o poder cria objetos de saber, fazendo-os emergir e acumular informações e as utilizar. Lembra, ainda, que para Foucault (FOUCAULT, $1993^{1}$ apud THIESEN, 2013) o poder não se dá, não se troca nem se retoma, mas se exerce. Só existe em ação e é, acima de tudo,

\footnotetext{
${ }^{1}$ FOUCAULT, M. Microfísica do Poder. Rio de Janeiro: Graal, 1993. p. 175.
} 
uma relação de força, um modo de ação sobre as ações do outro. Por isso, pressupõe a liberdade.

Thiesen destaca que "a memória como alvo político passa por determinados discursos e está aliada aos critérios de verdade vigentes na sociedade" (THIESEN, 2013, p. 29). Assim, seria preciso descrever a "racionalização presente nas instituições e observar como ela opera tanto no comportamento dos indivíduos como no conjunto das instituições que formam a sociedade. Isto porque as instituições retêm e esquecem num processo de racionalização" (THIESEN, 2013, p. 29-30).

Para Thiesen, "o comportamento e a prática é que fazem as instituições e definem o processo de institucionalização" (THIESEN, 2013, p. 30). As instituições trazem embutidos mecanismos de controle social, estabelecendo regras e padrões de conduta que venham a garantir seu funcionamento e o exercício de suas funções reprodutoras. Trata-se de reproduzir rituais que devem ser repetidos por força do hábito e com 0 apoio da memória. Nessa perspectiva, compreende-se por que as instituições lutam para preservar sua regularidade. Assim, a memória institucional abrangeria a memória organizacional, mas não ficaria limitada a ela. As relações de força é que determinariam o plano institucional e definiriam a organização, com base em sua legitimidade.

Nos arquivos, parte-se do princípio de que todas as etapas do trabalho intelectual de tratamento dos documentos arquivísticos são norteadas pelo estudo da instituição produtora do acervo, da legislação que rege a área, da estrutura administrativa do produtor e das funções e atividades que os geraram. Todo documento arquivístico se torna único, em razão de sua própria história. Para que se formem longas séries arquivísticas - capazes de refletir a ação da instituição produtora -, é necessário criar rotinas de trabalho e modos de tradição documental e fazer com que as regras sejam reconhecidas por todos e estejam na memória. Assim, é importante que em todas as etapas do ciclo vital dos documentos de arquivo os produtores e os usuários dos documentos reconheçam nos documentos seu trabalho e a instituição.

Outro elemento que deve ser levado em consideração nesse quadro de conceituação da memória institucional é que ela, segundo a análise fundadora de Thiesen, pode ser pensada como jogo de informações e práticas discursivas. A partir dessas considerações, a autora encaminha seu trabalho para uma discussão sobre representação, um conceito caro à Ciência da Informação (THIESEN, 2013, p. 46).

Ao tratar dos processos de institucionalização das relações sociais, Thiesen volta-se para as questões relativas à memória, encarada como um mecanismo de invenção social. Nesse percurso, define modalidades de memória. Por exemplo, aquela que se apoia em diversas superfícies de inscrição (ou, como preferimos, de suportes), "que produz uma infinidade de documentos, em seu amplo sentido, da mesma forma que reproduz a informação, conhecimento, dado, memórias", que constituiriam uma memória-arquivo. Para dar conta dessas memórias, teriam sido criadas as instituições-memória - arquivos, bibliotecas e museus -, que "organizam a memória da memória ao longo do tempo e são, por essa razão, 
encarregados da representação destas memórias" (THIESEN, 2013, p. 8081). Acreditamos que melhor seria pensar que essas instituições patrimoniais trabalham com legados simbólicos.

Nessa linha de raciocínio, a autora elenca, ainda, a memóriaacontecimento, que seria a memória-caos, responsável pela emergência do novo a partir das práticas já consolidadas; e a memória-hábito ${ }^{2}$, a qual tem a capacidade de criar comportamentos e economizar esforços, contrapondo-se à noção de memória-arquivo, a qual é importante por guardar informações que podem ser recuperadas para a manutenção de determinada ordem vigente.

\section{Memória-arquivo?}

A concepção de memória-arquivo interessa-nos especialmente neste artigo, pois, ao tratarmos dos arquivos - sejam eles as instituições arquivísticas públicas, que têm como atividades-fim a guarda de documentos permanentes, sua preservação e a promoção do acesso, ou as instituições privadas, como o serviço de arquivo de uma empresa, que executa as funções arquivísticas como atividade-meio -, acreditamos que nos dois casos o desempenho das atividades com a memória nos arquivos será fundamentado a partir das análises do contexto de produção dos documentos. Esse contexto de produção dos documentos e de seus sentidos é responsável por dar um caráter único ao documento de arquivo.

Ao situarmos nossa preocupação no modo como se opera com a noção/conceito de memória nos arquivos, é preciso lembrar o trabalho de José Maria Jardim (1996) ao enfatizar a importância da discussão no processo de avaliação e seleção de documentos arquivísticos e na constituição dos acervos permanentes/históricos dos arquivos públicos. Isso, na medida em que destaca que a memória nos permite considerar documentos socialmente relevantes, a ponto de justificar sua preservação permanente. Nesse processo de avaliação de documentos, o autor recomenda agir à luz da racionalidade técnica, sem desconsiderar a dimensão política do documento arquivístico e da própria avaliação arquivística.

Nesse ponto, preferimos direcionar nossa análise sobre memória institucional, arquivo e arquivologia guiados pelo debate sobre a historicidade do trabalho memorial das instituições arquivísticas. Afinal, até por vício de formação e pela experiência profissional nos arquivos, compreendemos que para a construção das memórias institucionais tornase mais eficaz, e não apenas celebrativa em pontos específicos da história

2 Joel Candau explica que a memória-hábito (ou memória repetitiva), termo cunhado por Henri Bergson, equivale a uma memória de baixo nível, ou protomemória. Ela é imperceptível e ocorre sem a tomada de consciência. Dela decorre o habitus, descrito por Pierre Bourdieu, de acordo com Candau (2016, p. 23). 
da instituição, como nas datas-redondas, em que é preciso que a instituição adote uma política de gestão de documentos arquivísticos e que se debruce sobre sua memória institucional e seus distintivos históricos.

Em nossas experiências profissionais, temos construído metodologias de trabalho de pesquisa para a escrita sobre memória institucional de arquivos públicos que podem ser caracterizadas como um plano de redação teatral, no caso de Ivana Parrela. ${ }^{3}$ Nelas, parte-se da apresentação dos atores envolvidos, tanto os produtores dos documentos como os gestores das instituições; do cenário no qual o arquivo se constituiu; e da trama de constituição do acervo. Ou seja, a "história arquivística" torna-se o tema da pesquisa. Em projetos recentes, Adalson Nascimento ${ }^{4}$ lidou com a história administrativa como base para 0 tratamento técnico de arranjo e a descrição de fundos documentais.

Levando tais experiências em consideração, infere-se que memória institucional, diferentemente da memória organizacional, não quer simplesmente organizar processos, procedimentos ou tarefas, mas sim apreender seu significado e sua personalidade, evidenciando sua posição e seu papel na sociedade, especialmente quando se trata de instituições arquivísticas. Para tanto, podem-se exemplificar alguns documentos arquivísticos que se tornam essenciais para a construção de memória institucional: ata de fundação da entidade, Missão, Visão e Valores corporativos, história da empresa, organograma legislação, apresentação institucional e código do bom governo.

Cabe destacar que essas são as tipologias documentais consideradas essenciais, ou clássicas, para a escrita da memória, ou história ${ }^{5}$, institucional. No entanto, hoje, as preocupações dos profissionais de arquivo com a construção de instrumentos de descrição mais dinâmicos e atualizados e a crescente disponibilização dos acervos em sítios eletrônicos têm levado à atualização das histórias arquivísticas dos acervos. O elemento "história arquivística" está previsto tanto na International Standard Archival Description (General) - ISAD(G) quanto em sua versão brasileira, a Norma Brasileira de Descrição Arquivística Nobrade. Seu objetivo é "oferecer informações referenciais sistematizadas sobre a história da produção e acumulação da unidade de descrição, bem como sobre a sua custódia" (BRASIL. Conselho Nacional de Arquivos, 2006, p. 34).

Nesse aspecto, vale destacar o movimento internacional na área para disseminar instrumentos de pesquisa minimamente padronizados, que culminou na elaboração das normas $\operatorname{ISAD}(G)$ e Nobrade, a partir de

\footnotetext{
${ }^{3}$ Cf. PARRELA (2012a; 2012b). Nos trabalhos, são discutidas as análises da trajetória do Arquivo Público Mineiro e do Arquivo Público da Cidade de Belo Horizonte, respectivamente.

${ }^{4}$ Cf. CHAMON; NASCIMENTO (2015) e LINHALES; NASCIMENTO (2014). Os textos apresentam os percursos investigativos da história arquivística que subsidiaram o tratamento técnico de fundos documentais custodiados pelo Arquivo do Centro Federal de Educação Tecnológica de Minas Gerais e pelo Centro de Memória da Educação Física, do Esporte e do Lazer da UFMG.

5 A distinção entre memória e história é recorrente na literatura das ciências humanas e sociais.

No verbete História, da clássica coletânea História e Memória, Jacques Le Goff reconhece a História como uma ciência, ainda que não como as outras ciências. Em seu entendimento, no verbete Documento/monumento, a história é a forma científica da memória coletiva (LE GOFF, 2003, p. 525).
} 
meados dos anos de 1990. Com esses novos norteadores, a história arquivística passou a ser mais valorizada nos instrumentos descritivos. Isso porque "as cores locais" se tornariam mais visíveis por meio das histórias dos conjuntos documentais. Dunia Llanes-Padron, ao refletir sobre a descrição na atualidade, entende que "a descrição archivística contemporânea tem como finalidade manter a autenticidade, veracidade e integridade dos documentos" (LLANES-PADRON, 2012, p. 175). ${ }^{6}$

Paralelamente a esse movimento nos arquivos, a Memória Institucional começou a ser tratada de forma sistemática a partir da década de 1970, como reflexo dos estudos sociológicos, antropológicos e históricos voltados à questão da memória. Nesse momento, principalmente nas empresas, percebeu-se que para seu crescimento era importante registrar e preservar sua memória, ou seja, criar lastro para seus produtos e serviços.

$\mathrm{Na}$ década de 1980, na França, foram criados os Centros de Arquivos do Mundo do Trabalho, subordinados aos Arquivos Nacionais, os quais coletavam arquivos privados com objetivos culturais e científicos, científicos, visando a "conservação definitiva da memória pertinente à empresa e aos sindicatos", conforme Goulart (2002, p. 11).

Na mesma época, no Brasil, a memória institucional começou a ser tratada de forma mais acentuada em Centros de Memória, nos órgãos públicos, em algumas instituições privadas e, com maior prevalência, em instituições universitárias. Paulo Roberto Elian dos Santos analisa o contexto:

Criados, respectivamente, em 1973 e 1974, o Centro de Pesquisa e Documentação da História Contemporânea do Brasil (CPDOC/FGV) e o Arquivo Edgard Leuenroth, da Universidade Estadual de Campinas (Unicamp) serviram de referência para inúmeras outras iniciativas que, na década de 1980, originaram centros de documentação e pesquisa, concebidos como espaços multidisciplinares voltados para atividades de investigação, preservação e difusão de acervos representativos da memória política, social e cultural do país. Ainda na década de 80, a Fundação Nacional Pró-Memória lançou o Programa Nacional de Preservação da Documentação Histórica (PróDocumento), cuja finalidade era preservar, por meio da assistência técnica a arquivos e atividades censitárias, os acervos privados de valor histórico (SANTOS, 2010, p. 110).

Fatores como fim da ditadura, processo de redemocratização, promulgação da Constituição de 1988 e início do acesso às novas tecnologias informáticas abriram a possibilidade de recuperar e/ou acessar informações para conhecer a história do País e disponibilizá-las de forma organizada e transparente à sociedade. Ainda podemos inserir nesse contexto o debate sobre a Lei de Arquivos brasileira, ou Lei $n^{\circ} 8159$, de 1991 (BRASIL. Presidência da República, 1991).

\section{O debate sob o olhar empresarial}

6 Tradução nossa de: "La descripción archivística contemporânea tiene como finalidad mantener la autenticidad, veracidad e integridad de los documentos". 
Para alguns autores, os primeiros trabalhos que podem ser caracterizados como memória institucional ocorreram na década de 1960, quando os pesquisadores acadêmicos estavam interessados em refletir sobre a estrutura/evolução industrial brasileira e em compreender a relação entre aspectos econômicos, ideologia e estrutura paternalista das instituições, de acordo com Gagete e Totini (2004).

Na década de 1980, a grave crise econômica e a redemocratização do País trouxeram grandes mudanças. Além do mercado mundial, o mercado interno também exercia pressão, "especialmente quanto ao consumidor final -, que passava a requerer novos parâmetros de qualidade e de comunicação institucional, exigindo de empresas e governos uma relação mais aberta e principalmente mais transparente". Isso mudava o foco não apenas do marketing, como também da administração dos recursos humanos e da relação empresas-comunidade (GAGETE; TOTINI, 2004, p. 118).

Informações organizadas e seguras para o dia a dia ou para momentos importantes de tomada de decisão fazem parte da rotina de qualquer tipo de instituição e tem como resultado dados, procedimentos, produtos e, consequentemente, toda a documentação desses processos que fazem parte da memória institucional, por estarem relacionados a sua trajetória. Essa discussão surgiu com mais força no período dos discursos empresariais. O que, normalmente, ocorria nessas instituições era a criação de locais específicos para a preservação dessa memória. Mas, por motivos financeiros ou de gestão ou por falta de planejamento, esses setores acabavam sendo desativados após a comemoração de alguma data redonda, que, muitas vezes, era o estopim para a constituição dos primeiros esforços memoriais. Em consequência, os documentos, a base para a construção da memória institucional, eram depositados em galpões ou locais de difícil acesso, inacessíveis aos públicos interno e externo. Porém, com a conscientização da importância estratégica da preservação da memória institucional, algumas instituições começaram a perceber que era preciso promover as mudanças organizacionais necessárias sem perder sua identidade, e isso se reflete até hoje nos Centros de Memória.

Além da preocupação com a produção de trabalhos acadêmicos sobre o assunto, entendeu-se que a memória institucional deveria refletir os processos vivenciados nas instituições de maneira mais transparente, assim como seus erros e acertos, conforme Nassar (2007):

A empresa que tem a intenção de se perpetuar no mundo de hoje, com vistas para o futuro, deve necessariamente legitimar suas atitudes, ações, posturas e, especialmente, ter consciência e dar conhecimento dos impactos de suas atividades no passado, no presente e no futuro em diferentes níveis, do comercial ao social. Aquela historinha mal contada ou a varrida do lixo para debaixo do tapete, já não são aceitas e colocam qualquer organização em risco (NASSAR, 2007b).

Assim, a memória se constituiu em um elemento de vital importância para as organizações no momento de reconstruir e 
representar suas experiências, com o objetivo de transcender a história corporativa. Essa memória, como definiu Jacques Le Goff, pode funcionar ou ser analisada de diferentes âmbitos, "os fenômenos da memória, em seus aspectos tanto biológicos como nos psicológicos, nada mais são que os resultados de sistemas dinâmicos de organização" e apenas existem "na medida em que a organização os mantém ou os reconstitui" (LE GOFF, 2003, p. 420-421) em processos de auto-organização.

Muitas vezes, nos esquecemos de que os atores se desenvolvem no âmbito das dinâmicas laborais, constituindo-se em fonte de grande importância no momento de reativar a memória, além de gerarem o conhecimento tácito ${ }^{7}$ para seu funcionamento contínuo. Nesse sentido, o capital social nas organizações resulta de um valor incalculável, principalmente porque os sujeitos, embora desenvolvam atividades particulares, é que criam redes tanto internas quanto externas, que, com o decorrer do tempo, vão ficar no quadro social da memória (usando o conceito de Maurice Halbwachs), no quadro organizacional e no quadro institucional. Por tanto, essa memória é um apanhado de conhecimentos provenientes de experiências que a organização [ou instituição] acumula ao longo dos anos com as pessoas, a cultura, os processos e os documentos (SPILLER; PONTES, 2007, p. 99).

Crippa afirma que "memória é uma palavra-chave na organização dos estoques de informação e de sua recuperação" (CRIPPA, 2010, p. 83), a qual, muitas vezes, dificulta o acesso a ela por parte usuário, devido, principalmente, à grande massa documental e informacional heterogênea gerada no dia a dia no ambiente laboral ou aos deficientes sistemas de informação, que não desempenham de forma eficiente o trabalho esperado.

A memória organizacional deve se complementar com a memória institucional, destacando a reflexão entre os aspectos econômicos, ideológicos e estruturais. Assim, "toda organização para se manter necessita de uma 'espinha dorsal' capaz de sustentar o todo organizacional, uma espécie de estrutura oficial com maior força de decisão, usada para legitimar os procedimentos propostos para o estabelecimento da estratégia organizacional utilizada em dado momento dentro da empresa" (RUEDA; FREITAS; VALLS, 2011, p. 84).

A principal diferença entre memória organizacional e memória institucional, nessa perspectiva, estaria no foco de cada atividade. Enquanto o termo memória organizacional leva à ideia da eficácia, que aceita mudanças em seu trajeto, o termo memória institucional remete às ideias de legitimidade, criação e identidade. Isso justifica sua escolha para este estudo, pois se conecta ao conceito que algumas empresas (ou instituições públicas) procuram construir para si de que identidade e reputação constituem a memória. Ainda seguindo a linha de raciocino de Nassar (2007a), que nos lembra de que já não basta oferecer o produto/serviço mais desejado, além das já conhecidas responsabilidades

Sobre conhecimento tácito, ver: CÂMARA, Mauro Araújo. Gestão do conhecimento tácito: um estudo de caso em uma organização pública de pesquisa e ensino em Minas Gerais. 2017. 213 f. Tese (Doutorado em Ciência da Informação) - Escola de Ciência da Informação, Belo Horizonte, 2017. 
social e ambiental, as instituições começam a se preocupar em apresentar um diferencial para o mercado: a responsabilidade histórica empresarial.

[...] Um conceito sistêmico, relacionado às atividades humanas especialmente a partir das organizações empresariais [que] reúne as responsabilidades comercial, legal, ambiental, cultural, social, etc. $[\ldots]$, e que só se constrói por meio do tratamento, preservação e disseminação da Memória Institucional (NASSAR, 2007b).

Outra diferença determinante entre memória organizacional e memória institucional se estabelece com a ideia de que uma organização possui seus meios, através dos quais o conhecimento do passado é recuperado em atividades do presente, determinando maior ou menor eficácia organizacional. As atividades que estão em jogo dizem respeito às diferentes formas de administração de tais organizações. De outro lado, é importante identificar uma instituição, definida por um conjunto de práticas finalizadas, com suas normas e regras.

Nas palavras de Camargo e Goulart, "entre os recursos produtivos de que dispõem as organizações para garantir sua continuidade, destacam-se, para além dos tangíveis ou materiais [...], aqueles que se convencionou reunir sob o nome de capital intelectual" (CAMARGO; GOULART, 2015, p. 41).

Marli Silva da Motta, ao discutir o processo de construção das comemorações e da memória institucional de um banco estatal nos anos de 1990 - o Banco Central -, aborda um aspecto que é bastante recorrente nos debates sobre memória nas instituições arquivísticas: Como dar conta da memória institucional de um órgão cuja história se confunde, muitas vezes, com a própria história do país ou da localidade onde a instituição está inserida? (1995, p. 1).

\section{0 lugar da memória institucional nos arquivos}

Diversos autores relacionam memória institucional com arquivo. Alguns entendem que o arquivo reflete, espelha, a memória. Por esse viés, o arquivo seria sinônimo de memória institucional. No entanto, vale relembrar o caráter polissêmico do conceito de memória, que perpassa diversas áreas do conhecimento humano. Assim, entendemos ser relevante explorar a relação entre memória institucional e arquivo.

Em nosso entendimento, o arquivo pode fornecer fontes para a memória institucional, mas não se confunde com ela. Em "Arquivos e memória coletiva: mais que uma metáfora, menos que uma analogia", a autora norte-americana Margaret Hedstrom faz uma interessante leitura sobre arquivo e memória coletiva. Para ela, há uma simplificação e generalização de conceitos de memória na literatura arquivística recente. Entende, também, que o arquivo participa da construção e da persistência da memória coletiva, não necessariamente com centralidade, já que tal construção se faz em paralelo com outros meios de transmissão de informações (HEDSTROM, 2016, p. 242).

$\mathrm{O}$ ponto de vista da autora é bem sintetizado na afirmativa de que 
[...] os documentos de arquivo não são representações da memória coletiva, e as instituições arquivísticas não são depósitos de memória coletiva. Ao contrário, os arquivos são fontes para a potencial descoberta ou recuperação de memórias que haviam sido perdidas. Uma vantagem particular que os arquivos possuem enquanto veículos de memória coletiva (além de sua persistência) é que eles podem permanecer insuspeitados e imperturbáveis enquanto as memórias individuais se esvaem, enquanto a memória coletiva é reconfigurada, ou até mesmo enquanto existem esforços conscientes de se apagar a memória (HEDSTROM, 2016, p. 255).

Nessa linha de pensamento, a autora sugere que os arquivos adquirem maior valor quando faltam elementos à persistência da memória coletiva e, portanto, os arquivos podem contribuir para as comunidades em busca de memória. Em consonância com Hedstrom (2016), Viviane Tessitore discute o tema "Memória e arquivos" e conclui:

Arquivo não é coincide com memória [sic]. O arquivo registra as ações no momento em que ocorreram, registro marcado, evidentemente, pelo contexto em que foi produzido; a memória reelabora continuamente o passado a partir das experiências presentes (TESSITORE, 2011, p. 174-175). Venâncio:

Outra colaboração sobre o mesmo tema é apresentada por Santos e

Os arquivos não são originalmente gerados com o objetivo da produção de memórias. [...] a documentação arquivística regula obrigações e direitos e sua forma de acumulação relaciona-se à dinâmica administrativa e funcional das instituições. Não obstante, uma vez constituídos, os arquivos servem de base para a construção de narrativas históricas, que elaboram ou reelaboram a memória de um indivíduo, de uma instituição ou de uma comunidade (SANTOS; VENÂNCIO, 2015, p. 60).

\section{Considerações Finais}

$\mathrm{Na}$ contemporaneidade, o funcionamento e a estrutura das organizações tornaram-se mais dinâmicos e menos estáveis. Em consequência, a memória institucional ganhou força como elemento de fixação da identidade e da personalidade das organizações. Tendo em vista a premissa de que os documentos de arquivo podem ser tomados como registros de memória institucional, a adoção de políticas de gestão de documentos arquivísticos é uma estratégia que tem sensibilizado cada vez mais as organizações.

A confiabilidade dos documentos arquivísticos contribui para a diferenciação deste tipo de registro de memória em relação a outros tipos de registros. Para Rousso, tal confiabilidade pode ser explicada pelo fato de o documento arquivístico ser contemporâneo aos fatos, por sua abundância e por ser funcional, instrumental, antes de ser tomado como vestígio sobre o passado (ROUSSO, 1996, p. 88). Significa que os agentes produtores do documento, ainda que não sejam neutros, estão mais 
próximos dos fatos, e por isso fornecem informações confiáveis, que, evidentemente, devem ser criticadas. O estatuto probatório, objetivo de qualquer documento arquivístico, reforça a sua confiabilidade e condiz com as noções de imparcialidade e autenticidade. A imparcialidade explica-se pela funcionalidade do documento arquivístico. Isso significa que "são parciais em relação à entidade produtora [...] são partes constitutivas de sua lógica interna". Ao mesmo tempo, são "imparciais em relação ao pesquisador" (CAMARGO, 2009, p. 435). Ao apresentar as propriedades do documento arquivístico, cunhadas pela arquivologia clássica, Eastwood afirma: "A autenticidade equivale a comprovar que a coisa em questão é o que afirma ser" (EASTWOOD, 2016, p. 27).

Depois de ponderarmos sobre a importância do documento de arquivo para a escrita de histórias institucionais, é preciso dar início a outro movimento de discussão sobre o lugar dessas narrativas dentro das instituições arquivísticas e mostrar como elas se aproximam e complementam o que se convencionou chamar em arquivologia de "história arquivística".

\section{Referências}

BRASIL. Conselho Nacional de Arquivos (CONARQ). NOBRADE: Norma brasileira de descrição arquivística. Rio de Janeiro: Arquivo Nacional, 2006.

BRASIL. Lei 8159 de 8 de janeiro de 1991. Dispõe sobre a política nacional de arquivos públicos e privados e dá outras providências. Diário Oficial da União, Brasília, 9 jan. 1991.

CAMARGO, A. M. de A.; GOULART, S. Centros de Memória: uma proposta de definição. São Paulo: Edições Sesc São Paulo, 2015.

CAMARGO, A. M. de A. Os arquivos e o acesso à verdade. In: SANTOS, Cecília Macdowell; TELES, Edson; TELES, Janaína de Almeida (Org.). Desarquivando a ditadura: memória e justiça no Brasil, volume II. São Paulo: Aderaldo \& Rothschild Editores, 2009.

CANDAU, J. Memória e identidade. São Paulo: Contexto, 2016.

CHAMON, C. S.; NASCIMENTO, A. Memória e trabalho: o arquivo histórico do Centro Federal de Educação Tecnológica de Minas Gerais. In: NASCIMENTO, A.; MORENO, A. (Org.). Universidade, memória e patrimônio. Belo Horizonte: Mazza Edições, 2015. p. 123-142.

CRIPPA, G. Memória: geografias culturais entre história e ciência da informação. In: MURGUIA MARANON, E. I. (Org.). Memória: um lugar de diálogo para arquivos, bibliotecas e museus. São Carlos: Compacta, 2010. p. 79-110.

EASTWOOD, T. Um domínio contestado, a natureza dos arquivos e a orientação da ciência arquivística. In: EASTWOOD, T.; MACNEIL, $H$. (Orgs). Correntes atuais do pensamento arquivístico. Belo Horizonte: Ed. UFMG, 2016. p.19-45. 
GAGETE, E.; TOTINI, B. Memória empresarial, uma análise da sua evolução. In: NASSAR, P.(Org.). Memória de empresa: história e comunicação de mãos dadas, a construir o futuro das organizações. São Paulo: Aberje, 2004. p. 113-126.

GOULART, S. Patrimônio documental e história institucional. São Paulo: Assoc. dos Arquivistas de São Paulo, 2002.

HEDSTOM, M. Arquivos e memória coletiva: mais que uma metáfora, menos que uma analogia. In: EASTWOOD, T.; MACNEIL, H. (Orgs.). Correntes atuais do pensamento arquivístico. Belo Horizonte: Editora UFMG, 2016. p. 237-259.

JARDIM, J. M. A invenção da memória nos arquivos públicos. Ciência da Informação, v. 25, n. 2, aug. 1996. Disponível em: <http://revista.ibict.br/ciinf/article/view/659>. Acesso em: 2 maio 2018.

LACOMBE, F. Dicionário de Administração. São Paulo: Saraiva, 2004.

LE GOFF, J. História e memória. Campinas: Editora da Unicamp, 2003.

LINHALES, M. A.; NASCIMENTO, A. O esporte e suas práticas nas linhas e entrelinhas de um processo de organização de arquivos. Acervo, v. 27, p. 38-50, 2014.

LLANES-PADRON, D. La descripcion archivística: um antes y um después marcado por Isad(g) y lós nuevos paradigmas archívisticos. In: VALENTIN, M. L. P. (Org.). Estudos avançados em Arquivologia. Marília: Oficina Universitária; São Paulo: Cultura Acadêmica, 2012. p. 155-179.

MOTTA, M. S. da. Histórias de vida e história institucional: a produção de uma fonte histórica. Rio de Janeiro: CPDOC, 1995. Disponível em: <https://bibliotecadigital.fgv.br/dspace/bitstream/handle/10438/6735/10 37.pdf>. Acesso em: 3 abr. 2018.

NASSAR, P. Reputação é memória. 2007a. Disponível em: <http://www.rp-bahia.com.br/biblioteca/trabalhos/nassar-completo.pdf>. Acesso em: 10 jun. 2017.

NASSAR, P. A mãe de todas as responsabilidades. 18 ago. 2007b. Disponível em: <http://terramagazine.terra.com.br/interna/0,,OI1837029-EI6786,00A+mae+de+todas+as+responsabilidades.html>. Acesso em: 10 jun. 2017.

PARRELA, I. D. Patrimônio documental e escrita de uma história da pátria regional: Arquivo Público Mineiro 1895-1937. São Paulo: Annablume; Belo Horizonte: PPGH-UFMG; Fapemig, 2012a. (Coleção Olhares).

PARRELA, I. D. As formas de comemorar: o projeto 20 Anos do Arquivo Público da Cidade de Belo Horizonte - Memória institucional e reflexão crítica sobre as práticas arquivísticas. In: CONVENCIÓN INTERNACIONAL DE ARCHIVISTAS, 4., San Bernardo, Chile. Anais... San Bernardo, Chile, 2012b. p. 1-13. 
ROUSSO, H. O arquivo ou o indício de uma falta. Revista Estudos Históricos, v. 9, n. 17, p. 85-91, 1996.

RUEDA, V. M. da S; FREITAS, A. de; VALLS, V. M. Memória Institucional: uma revisão de literatura. CRB-8 Digital, São Paulo, v. 4, n. 1, p. 78-89, abr. 2011. Disponível em: http://revista.crb8.org.br/index.php/crb8digital/article/viewFile/62/64>. Acesso em: 10 jun. 2017.

SANTOS, P. R. E. dos. Arquivística no laboratório: história, teoria e métodos de uma disciplina. Rio de Janeiro: Teatral; FAPERJ, 2010.

SANTOS, S.; VENÂNCIO, R. Arquivos institucionais e memória da Universidade Federal de Minas Gerais: um estudo dos arquivos de arquitetura. In: NASCIMENTO, A.; MORENO, A. (Orgs). Universidade, memória e patrimônio. Belo Horizonte: Mazza Edições, 2015. p. 59-82.

SPILLER, A.; PONTES, C. C. C. Memória organizacional e reutilização do conhecimento técnico em uma empresa do setor eletroeletrônico no Brasil. Revista Brasileira de Gestão de Negócios, v. 9, n. 25, 2007, p. 96-108. Disponível em: https://www.redalyc.org/html/947/94792508/ . Acesso em: 10 jul. 2017.

TESSITORE, V. Arquivos e centros de documentação: um perfil. In: ALMEIDA, J. R. de; ROVAI, M. G. de O. (Orgs). Introdução à história pública. São Paulo: Letra e Voz, 2011. p. 161-175.

THIESEN, I. Memória Institucional. João Pessoa: Ed. da UFPB, 2013. 